\title{
How Tact Influences Reputation
}

\author{
A Study of a Chinese K-Pop Fan Club on Sina Weibo
}

Yuqing Xue ${ }^{1}$

Writing across the University of Alberta, 2020

Volume 1, Issue 1, pp. 15-24

Published November 2020

\section{Introduction}

For this assignment, students analyzed everyday writing - writing that we might not think about in the same ways as we think about writing at a university-and how communities use this everyday writing to accomplish a particular goal. In this case, Yuqing Xue looked at how the Chinese fans of Korean pop music (K-pop) stars use tact to subtly persuade other fans to further the community's goals: to keep their idols' reputations intact and to make them as popular as possible. K-pop fan groups recently demonstrated the power of their coordinated action campaigns by booking tickets for a Trump rally that they had no intention of attending. These inflated numbers led the Trump campaign to believe that more supporters would attend their rally than did. This recent example reveals how the writing of communities that we believe to be trivial may wield power and influence in other contexts.

Keywords: Discourse community, communication, rhetoric, genre

(c) $(\$)$ This work is licensed under CC BY-NC-ND 4.o. To view a copy of this license, visit https://creativecommons.org/licenses/by-nc-nd/4.0.

\footnotetext{
${ }^{1}$ Correspondence: yuqing6@ualberta.ca.
} 


\section{Introduction}

Many nations have enshrined free expression as a fundamental right of individual citizens in their constitutions, which protects writers from interference when they articulate their perspectives (Vonnegut 66). Even though governments have promised to punish any infringement upon the freedom of speech, some writers realize that their opinions are different from the mainstream. They choose not to express their views rashly and directly to prevent any possible negative impact on their reputation. Instead, they hold back their thoughts, persuade, or communicate with tact. Using tact means asserting and reflecting perspectives by "facilitating and smoothing human relationships, avoiding offence, and overcoming obstacles" (Heyd 223). So how does the use of tact as a rhetorical strategy influence one's reputation online? To explore this relationship and interaction, I analyzed social media posts written on Chinese Korean pop music (K-Pop) fan sites. The fans on these sites often use tact to influence other fans and to encourage them to enhance their K-Pop idols' reputation. I will give more details about this discourse community in the background information and method sections. I will then show how tact is used to obtain the community's goals by analyzing three examples of social media posts.

\section{Background information about Chinese K-Pop fan clubs and Sina Weibo}

For this paper, I chose to study the Chinese Korean Pop Music (K-Pop) fan club, a discourse community established in the territories of Mainland China to worship and support contemporary popular music celebrities based in South Korea. This group matches the characteristics of a discourse community as described by linguist John Swales.

The Chinese K-Pop fan club:

$\rightarrow$ "Has a broadly agreed set of common public goals" (Swales 471). This group's purposes include supporting a K-Pop idol and protecting the idol's reputation on the internet.

$\rightarrow$ "Has acquired some specific lexis" (Swales 472). For example, the fan club often uses the phrase "to clean up Google search results" to refer to the action of repeatedly and consistently searching for positive content with the idol's name, which will push down problematic search results on Google search suggestions.

$\rightarrow$ "Has a threshold level of members with a suitable degree of relevant content and discoursal expertise" (Swales 473). This community has thousands of members. 
Experts in the community have sufficient funds to follow K-Pop stars to events, and these experts share their first-hand information and details with novices in the community.

$\rightarrow$ "Has mechanisms of intercommunication among its members" (Swales 472). This community uses Sina Weibo, a Chinese microblogging platform, to communicate.

$\rightarrow$ "Uses [mechanisms] primarily to provide information and feedback" (Swales 472). The Chinese-Speaking K-Pop fan club is a place for fans to share their idols' itinerary and strategies about attending supportive events. This community's most common communication channel is an online written mechanism. It is difficult for most Chinese fans to see their idols in real life and physically meet up with other members due to the long distance between China and South Korea.

$\rightarrow$ "Utilizes and hence processes one or more genres in the communicative furtherance of its aims" (Swales 472). There are several genres used to share information in Chinese K-Pop fan clubs, for example, group chats, email, microblogs, etc. I will mainly explain how the group uses Sina Weibo, a microblogging website and particular genres on the website to communicate.

With an increasing number of daily active user numbers, Sina Weibo, or Weibo, has become one of China's most extensive public social news aggregation sites. It is complex and challenging to analyze the popularity of Weibo, but the possible reasons may be the following:

$\rightarrow$ "Rhetorical": there is not a restriction about the content format on Weibo, which means it allows users to post pictures, videos, texts, or even live streaming (Dean 13);

$\rightarrow$ "Cultural": Weibo has tags and categories, which assists users in finding others who have similar interests (Dean 16); and

$\rightarrow$ "Social": Weibo updates users' news feed immediately, and it provides a repost and reply button for users to share opinions and spread posts widely (Dean 11).

These three aspects described above allow users to share information and receive feedback quickly, contributing to my research since I could observe the public's reaction when a person communicates with or without tact in the Chinese K-Pop fan groups.

\subsection{Cultural differences between fans in the Western world and East Asia}

Generally, Western celebrities are supported in China because of their music, whereas fans worship Korean music stars because of their public persona and appearance. In contrast to Western pop stars who generally sign a contract with entertainment agencies to promote their original music and albums, K-Pop idols are more like entertainment companies' merchandise. Every year, thousands of Korean teenagers participate in auditions multiple 
times, and entertainment companies select no more than $12 \%$ of these hopeful stars based on their innate ability (Ricaplaza). However, this is just the start of the dream journey for these young entertainers.

According to the websites of SMTown, YGFamily, JYPe (the three most prominent entertainment companies in South Korea), a successful agency generally chooses only 4-12 people to debut in one year. This decision is not based on trainees' originality or musical talent but their appearance and personality since the companies will find other artists to write and choreograph songs for them. Therefore, the reputation has become a standard of measurement for agencies and the public to decide if the idol is qualified to receive popularity and survive in the competitive market. Unlike Western pop stars, if a Korean celebrity does or says something wrong that may influence his/her reputation, such as using expletives and taking drugs, their agencies might expel them. This difference between the Western and Korean entertainment industries changes the ways and purposes in which fans support an idol. For instance, Korean entertainment companies regularly portray idols as ideal boyfriends and girlfriends because they reckon this kind of image could attract more followers and improve profits. This gives many fans the illusion of marrying one of these celebrities, making them willing to do anything for the K-Pop stars, "their future spouses"; commonly, these pop stars will hide or apologize for falling in love with someone because it will disappoint their fans. This image of idols may lead to an obsession with a celebrity, which is frequently considered incomprehensible and unacceptable in Western society but is a common phenomenon in $\mathrm{K}-\mathrm{Pop}$ fandom.

\section{Analysis of tact in social media posts in K-Pop fan groups}

For this essay, I will analyze three examples of social media posts in the Chinese $\mathrm{K}$-Pop fan groups on Weibo. I will explain the meaning of the posts and discover how communicating with tact was used to enhance the K-Pop idol's reputation.

A Chinese fansite posted the first example (Figure 1) to establish support for a Korean singer named Sehun. The fansite was trying to mobilize fans to purchase a magazine (which features Sehun on the cover) by politely and gently using the rhetorical appeal of logos and giving some data to explain and prove the importance of buying the magazine to readers, instead of commanding them to do so. The post first acknowledged fans' past contributions to the sales of the magazine. It then indicated that Sehun had received recognition for his influence and popularity from the public because of them. These persuasive behaviours share a sense of honour with the fans and indirectly arouse their enthusiasm for purchasing the new magazine. This avoids making fans feel offended and uncomfortable. In contrast, a direct command may have negatively influenced the relationship between individual fans and the fan site as generally, only immediate superiors can command people without 
hesitation. Thus, this example reveals that being tactful during negotiation helped increase profits and indirectly contributed to improving the reputation of the Korean idols.

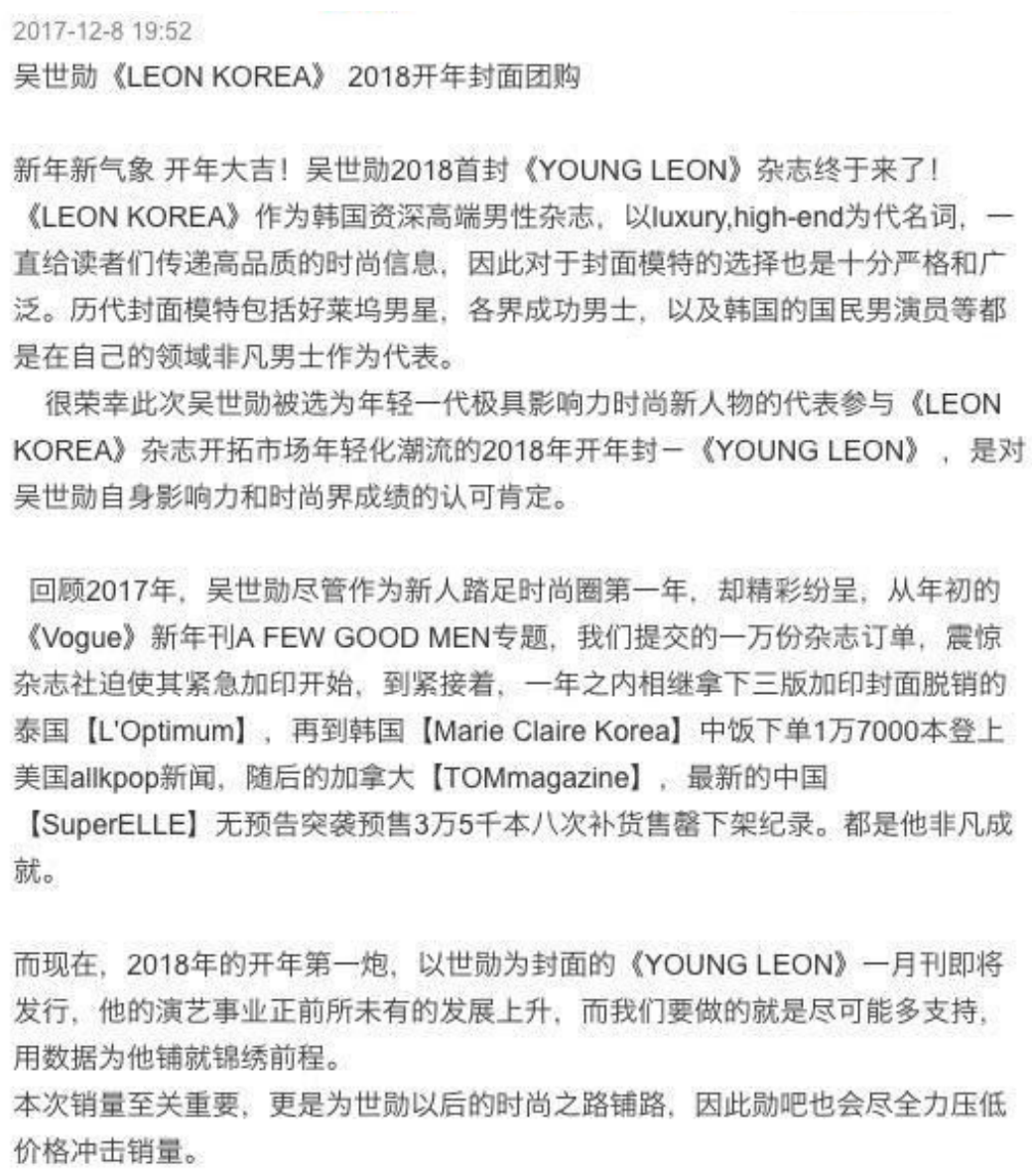

Figure 1. Translation: The first magazine 'Young Leon' ['Young Leon' is a theme of the magazine 'Leon Korea'], which features Sehun on the cover in 2018 is finally going to be published! [Explains what 'Leon Korea' and 'Young Leon' is.] We are so glad that Sehun has been chosen as the cover model of 'Leon Korean,' which is the best evidence to show that Sehun has won the recognition for his influence and popularity. Back in 2017, we purchased more than 50,000 magazines for Sehun. Some magazines even needed to print more copies for us! Even though 2017 was the first year for Sehun to start his modelling journey, his achievement was outstanding because of us. Now, this is a new start for Sehun. I hope everyone could keep supporting Sehun by purchasing 'Young Leon' because the sales of the magazine are representative of Sehun's reputation.

The second example of a post in this community was written by a Chinese fan on Weibo to support a South Korean actor Doh Kyungsoo ("Sina Weibo 1"). The fan was trying to prompt fans to clean up Doh's search engine results to protect their idols' reputation. However, it does not directly command fans to do the tasks. Instead, it first shows consideration and understanding to fans who were tired after the supportive event. It then 
tries to convince fans by indicating that only a minute's work can help maintain Kyungsoo's reputation. Even though the purpose of this post is to mobilize fans to maintain Doh's reputation, it uses tactful persuasion restraints from any possible infringement upon fans' freedom of choice. This example shows how the power of tactful persuasion contributes to reputation protection and maintenance.

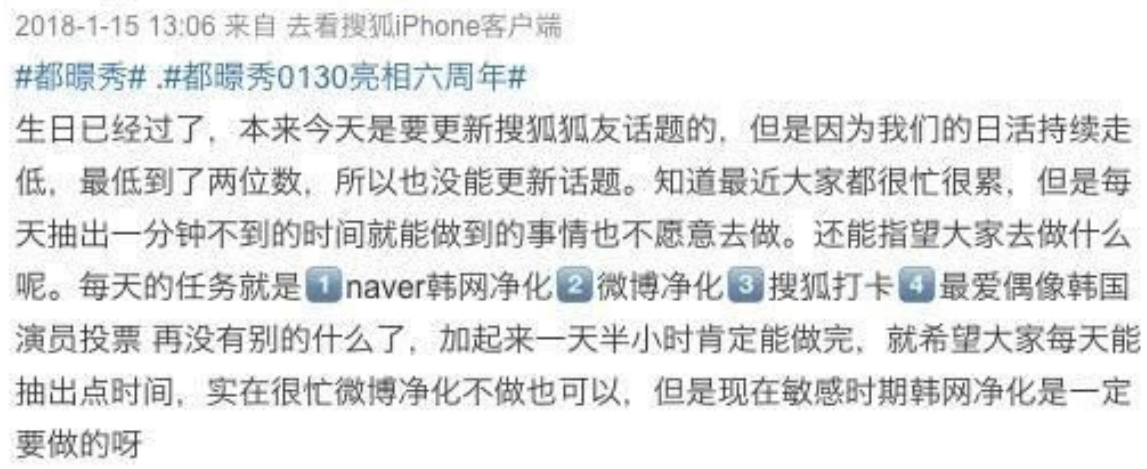

Figure 2. Translation: "I understand that you are tired after finishing the supportive event of celebrating Kyungsoo's birthday. However, I hope you can still take a minute to do the following tasks. 1. Clean up Kyungsoo's Naver ( $a$ Korean search engine) search result; 2. Clean up Kyungsoo's Weibo search result; 3. Participate in Kyungsoo's newest online event; 4. Vote for Kyungsoo. It will not take a long time, but it helps to protect Kyungsoo's reputation. I hope everyone can take up part of your time to do these tasks, or just to clean up the Naver search result.

The third example contains three Weibo posts ("Sina Weibo 3"). The first post (Figure 3) was written by a Chinese idol named Xukun Cai. This Chinese idol uploaded his new album cover and title to Weibo. However, because the song cover image was similar to a song cover image used by a Korean band named Hyukoh, the Chinese idol was accused of plagiarism by the Korean band's fans without evidence (Figures 4 and 5). To prove their idol's innocence, the supporters of Cai privately messaged the visual artist who drew the cover for the Korean band. It ended up that the same artist created both the covers. By expressing opinions without thoughtful consideration or communicating without tact, the accusers' reputation has been affected, even though the band's fans have apologized to Cai. 


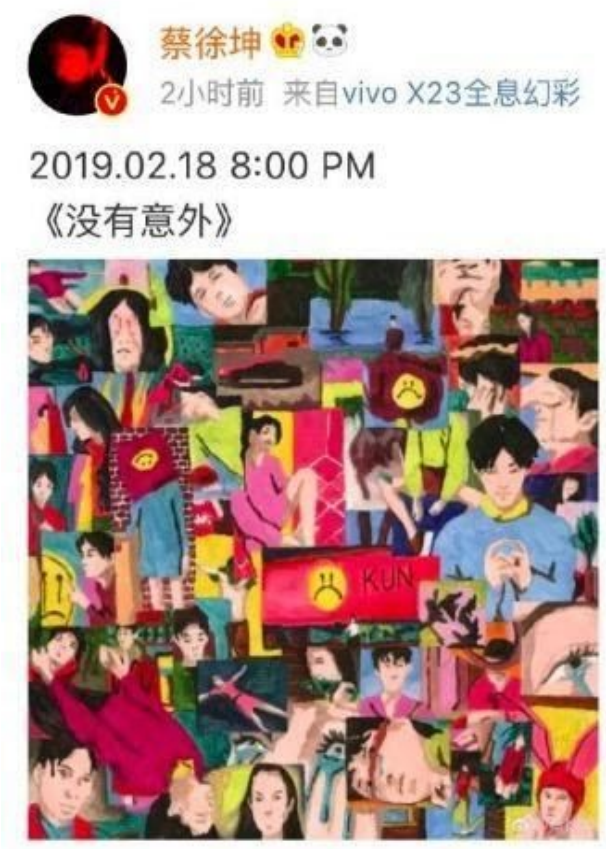

Figure 3. New album cover by Xukun Cai

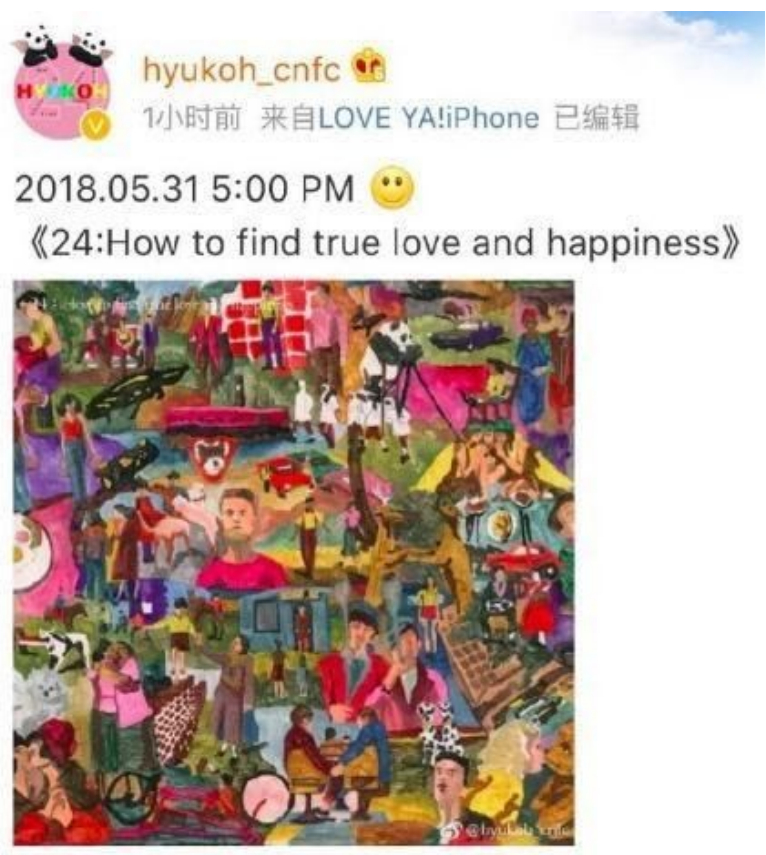

Figure 4. One thing that needs to be clarified is that the smiley face emoji that does not show teeth in Figure 4 generally refers to sarcasm in Chinese social media culture. 


\section{想到谈到这张主打love ya时吴赫说他会为这世上所 有的恋人应援。所以封面会是繁复的色彩和不同的情 侣。我想要说的是, 内在空无一物的躯壳根本撑不起 这份独特, 抄也只能抄个表面, 低级又无聊。}

Figure 5. Translation: "[...] All I want to say is that his (the main vocalist of the band) album cover is still the special and unique one even though you plagiarized it. You can never copy his spirit. Shame on you." There is a significant amount of expletives in the comments area under the posts.

\section{Conclusion}

As Freedman and Sears indicate, "people actively avoid being confronted with arguments counter to their own opinions" (57). Presenting audiences directly with perspectives that might not be acceptable, and that might accidentally offend them may cause them to reject these perspectives. It is necessary to convince readers progressively and to use a strategy of communication with tact to avoid offending the fans. Because many discourse communities use social networking posts to communicate and because their posts are usually public to all users on the platform, tactful speech may persuade outsiders' to have positive opinions of the community. Members of the discourse community should speak politely and respectfully to avoid offending unintentionally; in other words, they should use tact to maintain their reputation and that of their idols.

\section{Works Cited}

Dean, Deborah. "Explaining Genre Theory." Genre Theory: Teaching, Writing, and Being, 2008, pp. 8-26. WRS 101: Exploring Writing, University of Alberta, 2019, Course Pack.

Freedman, Jonathan L., and David O. Sears. "Selective Exposure." Advances in Experimental Social Psychology, vol. 2, 1965, pp. 57-97..

Heyd, David. "Tact: Sense, Sensitivity, and Virtue." Inquiry, vol. 38, no. 3, 1995, pp. 217-231. https://doi.org/10.1080/00201749508602387.

JYPe. JYP Entertainment. http://www.jype.com/. Accessed 15 September 2020.

Ricaplaze, Mae A. "What percentage of people who become trainees at JYP and SM actually debut?" Online posting. 30 Jun 2018. Quora. Quora.com. Web. https://www.quora.com/What-percentage-of-people-who-become-trainees-at-JYP-and-SM-actu ally-debut. Accessed 15 September 2020.

Sina Weibo 1. Sina Crop, 2018. www. weibo.com/3675857830/FEsQMmbP6?type=comment. Accessed 15 September 2020. 
Sina Weibo 2. Sina Crop, 2017.

https://www.weibo.com/2858947502/FyJgNze7H?type=comment\#_rnd1554522115848.

Accessed 15 September 2020.

Sina Weibo 3. Sina Crop, 2019.

https://www.weibo.com/6809086183/Hgw5rEOPr?refer_flag=1001030103_\&type=comment\#_r nd1553591013133. Accessed 15 September 2020.

SMTOWN. SM Entertainment, 2019. https://www.smtown.com. Accessed 15 September 2020.

Swales, John. "The Concept of Discourse Community." Genre Analysis: English in Academic and Research Settings. Boston: Cambridge UP, 1990. 21-32. Writing about Writing: Downs and Wardle. Boston: Bedford St Martins, 2011. 466 - 473. WRS 101: Exploring Writing, University of Alberta, 2019, Course Pack.

Vonnegut, Kurt. "How to Write with Style." IEEE Transactions on Professional Communication, PC-24, no. 2, June 1981, pp. 66-67. WRS 101: Exploring Writing, University of Alberta, 2019, Course Pack.

YGFamily. YG Entertainment, 2019. http://www.ygfamily.com/. Accessed 15 September 2020. 
Xue | How Tact Influences Reputation I Writing across the University of Alberta

This page intentionally left blank 